\title{
EEffects of three months of water-based exercise training on metabolic syndrome components in older women \\ Efecto de tres meses de entrenamiento con ejercicios acuáticos sobre componentes del síndrome metabólico en adultas mayores

\author{
Paulina Yesica Ochoa-Martínez, *Javier Arturo Hall-López, *Daniel Piña Diaz, *Diego Armando Zarate Trujillo, **Ana Maria \\ Teixeira \\ * Autonomous University of Baja California (México), ** University of Coimbra (Portugal)
}

\begin{abstract}
The purpose of this study was to evaluate the effects of water-based exercise training on metabolic syndrome components in older women. The subjects were randomly divided into an experimental group who participated in the water-based exercise training and a control group who was not involved in the training and remained sedentary. The quantification of clinical and biochemical parameters of abdominal obesity, atherogenic dyslipidemia, elevated blood pressure and insulin resistance without glucose intolerance by a medical and laboratory evaluation to assess the presence of metabolic syndrome components was done according to the guidelines of the National Cholesterol Educational Program Adult Treatment PanelIII (NCEP ATP-III). The training protocol consisted of water-based exercise training sessions 5 times per week during 12 weeks of intervention, executed in a pool of 1.3 meters divided into three phases: a 10 -minute warm-up, 30 minutes of aerobic exercise at $50 \%-60 \%$ of maximum heart rate (monitored by heart rate monitor) and a 10 minute cool down. As a statistical method to compare the results between groups of variables pre and post training, the statistical analysis ANOVA mixed 2 X 2 (group X measurement) was done using SPSS version 21. The results for the metabolic syndrome components only indicated statistically significant interactions for triglycerides mg.dl-1 ( $\mathrm{p}=0.002)$ between the groups and the measurements. Thus, the training program produced significant benefits on metabolic health indicators in particular decreasing triglycerides.
\end{abstract}

Keywords: Older Women, Metabolic Syndrome, Exercise.

Resumen. Objetivo: Evaluar los efectos del entrenamiento con ejercicio acuático sobre los componentes del síndrome metabólico en adultas mayores. Los participantes se dividieron en un grupo experimental y un grupo control que permaneció sedentario. La presencia de componentes del síndrome metabólico se evaluó de acuerdo con las directrices del Programa Nacional de Educación en Colesterol (NCEP-III) que evalúa los parámetros clínicos y bioquímicos de obesidad abdominal, dislipidemia aterogénica, presión arterial y resistencia a la insulina sin intolerancia a la glucosa. El protocolo de entrenamiento consistió en sesiones 5 veces por semana durante 12 semanas, divididas en tres fases: calentamiento 10 minutos, 30 minutos de ejercicio aeróbico al 50\% -60\% de la frecuencia cardíaca máxima y relajación 10 minutos. Como método estadístico para comparar los resultados entre grupos de variables pre y post, se realizó el análisis de varianza (ANOVA) mixta 2 X 2. Los resultados en los componentes del síndrome metabólico solo indicaron interacciones estadísticamente significativas para los triglicéridos mg.dl-1 ( $\mathrm{p}=0.002)$ entre los grupos y las mediciones. Por lo tanto, el programa de entrenamiento resulto beneficioso sobre los indicadores de salud metabólica, en particular la disminución de triglicéridos.

Palabras clave: adultas mayores, síndrome metabólico, ejercicio.

\section{Introduction}

The aging process is characterized by the progressive decline of organ and systems functions (Fulop et al., 2010). Metabolic syndrome is a health disease complication that has been strongly associated whit sedentary lifestyle in elderly women (Colpani et al., 2013), the complex nature of metabolic syndrome involving five major clinical components: abdominal obesity, atherogenic dyslipidemia, elevated blood pressure and insulin resistance without glucose intolerance in potentially harmful combinations that significantly rise cardiovascular risk (Luk et al., 2008), that mainly appears after sixty years, with the highest rates of cardiovascular diseases leading to greater healthcare costs (Sicras-Mainar et al., 2013), and affect the quality of life of these population (Okosun et al., 2013; Bohórquez et al., 2014).

Evidence from quasi-experimental studies in elderly practitioners of physical exercise in modalities such as aerobic endurance and strength showed beneficial results on metabolic syndrome components (Kim et al., 2011; Tan et al., 2012; Wang et al., 2012), This study applied a water-based exercise training, than carried out performing rhythmicgymnastic activities in an aquatic environment, that simultaneously counteracts gravity and increases physical capabilities (Kamioka et al., 2010). This type of exercise is especially recommended for people who have limitations with exercise on dry land (Kamioka et al., 2011) and which in the last ten years, has taken popularity and preference among elderly adults by taking advantage of the properties of water in order to provide fluidity and a wider range in movements while diminishing the risk of injuries due to impact (Kamioka et al., 2010; Kamioka et al., 2011). It was found that water-exercise in elderly women provides significant improvement in several aspects of well-rounded, physical

Fecha recepción: 29-11-17. Fecha de aceptación: 23-07-18

Javier Arturo Hall-López

javierhall@uabc.edu.mx function, including postural balance and health-related aspects of fitness (Takeshima et al., 2002; Sanders et al., 2013). It is unclear if a waterbased exercise program provides benefits in the metabolic syndrome components in elderly women. It is important to plan and prescribe adequate exercise for the needs of elderly adults and to minimize their health problems, this in turn, will provide them with an adequate level of physical performance, the latter which is crucial in order to maintain good overall health (Chodzko-Zajko et al., 2009; Romo et al., 2011; Villarreal et al., 2016); The present study proposes to help answer the remaining question: Can a water-based exercise training improve metabolic syndrome components in older women? In this study, waterbased exercise training was identifying as the independent variable and the five major clinical components of metabolic syndrome: abdominal obesity, atherogenic dyslipidemia, elevated blood pressure and insulin resistance without glucose intolerance as dependent variables. Two hypotheses were establish, one scientific and the other statistical: the scientific hypothesis anticipates that after adult women participated in the water-based exercise training, noticeable improvement will occur in the components of metabolic syndrome in older women; the statistical hypothesis in null and alternative form, establishing as the acceptance or relative criteria, the level of $\mathrm{p}<0.05$.

\section{Methods}

\section{Participants and setting}

The study design was quasi-experimental with non-probabilistic and convenience sampling. Subjects with interest in joining an aquatic stimulation program in the aquatic complex of the Faculty of Sports at the Autonomous University of Baja California were recruited. The sample consisted of 26 older women over 60 years old, apparently healthy who meet the following criteria: ambulation capacity, not have performed a systematical routine of exercise in the previous six months, divided randomly into one experimental group ( $n=16$, age of $67.5 \pm 5.4$ years old) that partook in the water-based exercise training and one 
control group ( $\mathrm{n}=10$, age of $67.4 \pm 4.7$ years old) who did not take part of the exercise program, maintained their normal everyday activities without performing any sort of systematic physical activity during the 12 weeks of the intervention program.

The present study followed the ethical principles regarding human experimentation proposed by the Helsinki declaration (Puri et al., 2009). All the participants signed a letter of consent, which explained the objective of the investigation, its evaluation protocols, possible risks, benefits, consequences, emergency procedures and consensus of participation as a volunteer, in order to participate in the study.

\section{Measures and procedures}

Quantification of clinical and biochemical parameters by a medical and laboratory were assessed in order to determine the presence of metabolic syndrome components according with the guidelines of the National Cholesterol Educational Program Adult Treatment Panel-III (NCEPATP-III), using the following procedures: blood samples were collected in the morning from 7:00 a.m. to 8:30 a.m. after 12 hours of fasting and 48 hours of rest from physical activity, 5 millimeters of venous blood were collected by a certified biochemist and were placed in EDTA tubes to evaluate the biochemical variables of total cholesterol, high density lipoprotein cholesterol and triglycerides. The values were determined using an enzymatic colorimetric method and HDL-C with a homogeneous enzymatic assay in which enzymes modified by Polyethylene Glycol produce the separation in presence of magnesium and dextrin sulfates at the same time of analysis. Quantification was performed in a modular selective multichannel photometric auto analyzer P800 (Roche Diagnostics), and plasma blood glucose in an auto analyzer by the method of glucose oxidase-peroxidase (Beckman C5 Cincron, Bayer). The clinical quantification of blood pressure was obtained after a 15 minutes sitting at rest by a sphygmomanometer (Omron hem713c) and the umbilical abdominal circumference was measured by a Lufkin metal anthropometric tape.

Metabolic syndrome was diagnosed in those women who had three or more of the following criteria: abdominal obesity (UAC $>88$ cm), TG values e» $150 \mathrm{mg}^{-1 l^{-1}}$, HDL-C values $\left\langle 50 \mathrm{mg}^{-1} \mathrm{dl}^{-1}\right.$; BP values e» 130/85 mmHg, or taking antihypertensive treatment, and plasma fasting

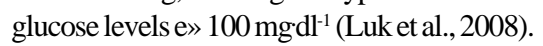

The subjects of this study were put through a water-based exercise training of moderate aerobic intensity in accordance with the standards established by the American College of Sports Medicine (ChodzkoZajko et al., 2009) and the American Heart Association (Nelson et al., 2007) also the standards \& guidelines for aquatic Fitness programming from the Aquatic Exercise Association (AEA).

The training consisted of 60 water-based exercise sessions with an exercise frequency of 5 times a week. The volume was set at 50 minutes per session, this being divided into 10 minutes of warm-up, 30 minutes of workload with progressively incremental intensities of $50 \%$ of maximum heart rate frequency for the first 6 weeks and $60 \%$ for the final 6 weeks of the program, using the formula Max HR=208-0.7x age (Tanaka etal., 2001), exercising through alternating movements between arms and legs, monitored using a heart rate monitor Polar FT $7^{\circledR}$ (Finland) followed by 10 minutes of cool down.

The statistical procedures proposed for an adequate analysis of this investigation were to characterize the sample and evaluate the hypothesis in the following manner:

Using descriptive statistical techniques the investigated universal sample was characterized and a description of the evaluated data was produced. Using methods of localization and dispersion in the standard deviation was then calculated and used to verify the sample symmetry (Thomas et al., 2001). The acquired statistical results were processed into charts and graphs using SPSS 21 software. The Shapiro-Wilk test was use in order to determine the normality of the groups and the homogeneity of the sample.

\section{Statistical analysis}

With the goal of establishing all the possibilities of comparison inter and intra group mixed 2 x 2 (groups $x$ measurements) (ANOVA) variance analysis tests were performed for the variables with the purpose of maintaining the scientific validity of the research. The significance level of $\mathrm{p}<0.05,95 \%$ probability of accuracy of the results or negative event with a probability of $5 \%$ per case. Percentage changes (Ä\%) were also calculated for each study group [(Mean post - Mean pre)/ Mean pre] x 100 (Vincent, 1999).

\section{Results}

The participants in the present study were 26 elderly women divided randomly into one experimental group $(n=16$, age of $67.5 \pm 5.4$ years old) that partook in the water-based exercise training and one control group ( $\mathrm{n}=10$, age of $67.4 \pm 4.7$ years old) who did not take part in the exercise program, the general characteristics of the sample can be observed in Table 1.

\begin{tabular}{|c|c|c|c|c|}
\hline \multirow[t]{2}{*}{ Variables } & \multicolumn{2}{|c|}{ Experimental $(\mathrm{n}=16)$} & \multicolumn{2}{|c|}{ Control $(\mathrm{n}=10)$} \\
\hline & Pre & Post & Pre & Post \\
\hline Body weight mass (kg) & $74.09 \pm 10.74$ & $73.27 \pm 10.81$ & $76.26 \pm 15.17$ & $76.29 \pm 15.70$ \\
\hline Height (cm) & $155.95 \pm 5.78$ & $155.90 \pm 5.72$ & $153.20 \pm 5.86$ & $152.41 \pm 6.19$ \\
\hline $\begin{array}{l}\text { Umbilical abdominal } \\
\text { circumference }(\mathrm{cm})\end{array}$ & $98.7 \pm 10.6$ & $96.1 \pm 12.3$ & $107.3 \pm 10.8$ & $107.3 \pm 10.8$ \\
\hline Sistolic blood pressure $\mathrm{mm}$ & $121 \pm 18.3$ & $121 \pm 10.1$ & $143.6 \pm 12.7$ & $143.6 \pm 12.7$ \\
\hline Diastolic blood pressure $\mathrm{mmHg}$ & $72.5 \pm 15.2$ & $71.3 \pm 22.3$ & $77.5 \pm 5.5$ & $77.5 \pm 5.5$ \\
\hline $\begin{array}{l}\text { High density lipoprotein } \\
\text { cholesterol mg.dl-1 }\end{array}$ & $46 \pm 7.98$ & $49 \pm 7.65$ & $40.7 \pm 7.4$ & $40.7 \pm 7.4$ \\
\hline Triglycerides $\mathrm{mg}_{\mathrm{dl}}{ }^{-1}$ & $174.4 \pm 24.4$ & $126.4 \pm 26.1$ & $169.2 \pm 32.2$ & $165.2 \pm 55.4$ \\
\hline Glucose mg.dl-1 & $82.2 \pm 11.9$ & $93.2 \pm 5.3$ & $91.5 \pm 8.5$ & $89.5 \pm 8.6$ \\
\hline
\end{tabular}

The results of theANOVA $2 \times 2$ tests indicated statistically significant interactions existed on Triglycerides mg.dl- $1(\mathrm{p}=0.002)$ between the groups and the measurements, neither statistically significant changes were found between groups $(\mathrm{p}=0.409)$ but it showed statistically significant on the measurements ( $\mathrm{p}=0.119$ ) (Figure 1$)$. For the variables of abdominal obesity, high density lipoprotein cholesterol, elevated blood pressure and insulin resistance without glucose intolerance, the results of the ANOVA 2 x 2 tests indicated no statistically significant interactions existed

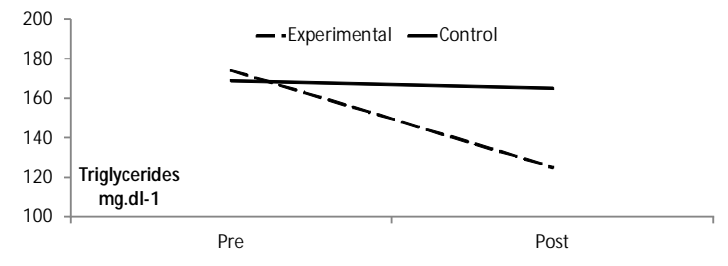

Graph 1. Changes in the Triglycerides mg.dl-1among the participants of the study ( $\mathrm{n}=26$ ).

The percentage changes (? \%) of metabolic syndrome components of each study group were calculated [(Mean post - Mean pre)/ Mean pre] x 100. The evidence is showed the experimental group $(\mathrm{n}=16)$ compared with control group $(\mathrm{n}=10)$ in table 2 , before and after 12 weeks of water-based exercise training.

Table 2 .

Percentage changes (? \%) of clinical and biochemical metabolic syndrome components in older women $(\mathrm{n}=26)$.$$
\text { Variables }
$$

Umbilical abdominal circumference $(\mathrm{cm})$

Sistolic blood pressure $\mathrm{mmHg}$

Diastolic blood pressure $\mathrm{mmH}$

High density lipoprotein cholesterol mg dd-1

Triglycerides $\mathrm{mg} \cdot \mathrm{dl}^{-1}$

Glucose mg.dl-1

\begin{tabular}{cc} 
Experimental $(\mathrm{n}=16)$ & Control $(\mathrm{n}=10)$ \\
\hline$-2,63$ & 0,00 \\
0,00 & 0,00 \\
$-1,66$ & 0,00 \\
6,52 & 0,00 \\
$-27,52$ & $-2,82$ \\
13,38 & $-2,19$
\end{tabular}

\section{Discussion}

Cross-sectional research studies associate high levels of physical activity and optimal metabolic syndrome components in the elderly (Ford, 2005; Colpani et al., 2013), quasi-experimental pre and posttest designs where the independent variable is exercise and abdominal obesity, high density lipoprotein cholesterol, elevated blood pressure and insulin resistance without glucose intolerance are the dependents variables as indicators of metabolic syndrome not always show significant changes after 12 to 48 weeks of aerobic, strength and stretching exercise programs in the elderly (Yamaoka \& Tango, 2012; Pattyn et al., 2013); These 
results were similar and congruent with studies carried out previously on elderly adults that found significant changes on improve lipid profile (Tan et al., 2012), although the percentage changes (Ä\%) in the experimental group was better that the control.

In the present study aerobic training was emphasized and the recommendations for prescribing exercise for elderly adults set by the American College of Sports Medicine (Chodzko-Zajko et al., 2009) and the American Heart Association (Nelson et al., 2007); these recommendations were followed by: establishing the duration of the exercise program to 3 months and adapting the volume of training to 5 times per week with progressive overload beginning at $50 \%$ of maximum heart rate frequency for the first 6 weeks and $60 \%$ for the last 6 weeks. As in other studies a systematic program of controlled dieting and exercise would greatly enhance the results obtained when evaluating the five metabolic syndrome components (Yamaoka \& Tango, 2012; Pattyn et al; 2013). However, in the current study environmental co variables that could have effectively altered the results obtained, such as lifestyle, diet and overall physical activity were not monitored or controlled (Araújo et al., 2015).

Systematic review and meta-analysis of water-based exercise training clearly show than improvements in musculoskeletal conditions (Barker et al., 2014; Heywood et al., 2017, Hall Lopez et al., 2017; Hall Lopez et al., 2018). According to our knowledge in academic literature there are few studies that show the effects of water-exercise on metabolic syndrome components in older women. Based on the established hypothesis, it is conclusive that 3 months practice of water-based exercise training by older women was not effective in reducing the metabolic syndrome components. However, further studies must be performed in order to corroborate the results obtained on these variables by a water-based exercise training modality. Methodological designs of subsequent studies must present changes such as: a longer time of water-based exercise training, evaluation of the effects of post-training rest on the variable, application on both genders and on different age groups, a larger «n» sample that in return will provide more validity to the inferential statistic when analyzing the results of the experiment while consequently providing the possibility to extrapolate the results to subjects with similar characteristics. The express purpose of these studies would be to obtain results that could serve as a reference for planning, execution and evaluation of future interventions directed at minimizing the predisposition of elderly women to suffer from metabolic syndrome. This in turn, will help researchers and professionals who work with this segment of the population to better understand more factors in order to provide better attention with physical exercise.

\section{Acknowledgment}

The study was funded by the Direction of academic achievement of the Secretariat of Public Education (SEP) in order to cooperate in a short term research between the Autonomous University of Baja California and the University of Coimbra (Protocol 511-6/17-5169).

\section{References}

Araújo, J.P., Neto, G.R.,Loenneke, J.P., Bemben, M.G.,Laurentino, G.C., Batista, G,Silva, J.C., Freitas, E,D. \& Sousa, M.S. (2015). The effects of water-based exercise in combination with blood flow restriction on strength and functional capacity in post-menopausal women. Age (Dordr). 37(6):110. doi: 10.1007/s11357-015-9851-

Barker, A.L., Talevski, J., Morello, R.T., Brand, C.A., Rahmann, A.E. \& Urquhart, DM. (2014). Effectiveness of aquatic exercise for musculoskeletal conditions: a meta-analysis. Arch Phys Med Rehabil, 95(9):1776-86. doi: 10.1016/j.apmr.2014.04.005.

Bohórquez, M. A., Lorenzo, M \& García A. J. (2014) Actividad física como promotor del autoconcepto y la independencia personal en personas mayores. Revista Iberoamericana de Psicología del Ejercicio yel Deporte, 9 (2) 533-546.
Chodzko-Zajko, W.J., Proctor, D.N., Fiatarone, Singh M.A., Minson, C.T., Nigg, C.R., Salem, G.J. \& Skinner J.S. (2009). American College of Sports Medicine position stand. Exercise and physical activity for older adults. [Practice Guideline].Med Sci Sports Exerc, 41(7):1510-30. doi: 10.1249/MSS.0b013e3181a0c95c.

Colpani, V., Oppermann, K. \& Spritzer, P.M. (2013). Association between habitual physical activity and lower cardiovascular risk in premenopausal, perimenopausal, and postmenopausal women: a population-based study. Menopause, 20(5):525-31. doi: 10.1097/ GME.0b013e318271b388.

Ford, E.S. (2005). Risks for All-Cause Mortality, Cardiovascular Disease, and Diabetes Associated With the Metabolic Syndrome. Diabetes Care,28(7):1769-78.

Fulop, T., Larbi, A., Witkowski, J.M., McElhaney, J., Loeb, M., Mitnitski, A. \& Pawelec, G. (2010). Aging, frailty and age-related diseases. Biogerontology, 11(5):547-63. doi: 10.1007/s10522-0109287-2.

Hall López, J.A., Ochoa Martínez, P.Y., Alarcón Meza, E. I., MoncadaJiménez, J. A., Garcia Bertruy, O. \& Martin Dantas, E. H. (2017). Programa de entrenamiento de hidrogimnasia sobre las capacidades físicas de adultas mayores / Hydrogymnastics training program on physical fitness in elderly women. Rev Int Med Cienc Ac, 17(66):283-298.

Hall López, J. A., Ochoa Martínez, P. Y., Lara Monzon, C. O., Gomes de Souza Vale, R. (2018). Effects of four months of periodized aquatic exercise program on functional autonomy in postmenopausal women with parkinson's disease. Retos, 33: 217-220.

Heywood, S., McClelland J, Mentiplay B., Geigle, P., Rahmann, A, \& Clark, R. (2017). Effectiveness of Aquatic Exercise in Improving Lower Limb Strength in Musculoskeletal Conditions: ASystematic Review and Meta-Analysis. Arch Phys Med Rehabil, 98(1):173186. doi: 10.1016/j.apmr.2016.08.472.

Kamioka, H., Tsutani, K., Okuizumi, H., Mutoh, Y., Ohta, M., Handa, S., Okada, S., Kitayuguchi, J., Kamada, M., Shiozawa, N. \& Honda, T. (2010). Effectiveness of aquatic exercise and balneotherapy: a summary of systematic reviews based on randomized controlled trials of water immersion therapies. J Epidemiol, 20(1):2-12.

Kamioka, H., Tsutani, K., Mutoh, Y., Okuizum, H., Ohta, M., Handa, S., Okada, S., Kitayuguchi, J., Kamada, M., Shiozawa, N., Park, S.J., Honda, T. \& Moriyama, S. (2011). A systematic review of nonrandomized controlled trials on the curative effects of aquatic exercise. Int J Gen Med, 25;4:239-60. doi: 10.2147/IJGM.S17384 .

Kim, S.H., Kim, M., Ahn, Y.B., Lim, H.K., Kang, S.G., Cho, J.H., Park, S.J, \& Song, S.W. (2011). Effect of dance exercise on cognitive function in elderly patients with metabolic syndrome: a pilot study. J Sports Sci Med, 10(4):671-8.

Luk, A.O., Ma, R.C., So, W.Y., Yang, X.L., Kong, A.P., Ozaki, R., Ko, G.T., Chow, C.C., Cockram, C.S., Chan, J.C. \& Tong, P.C. (2008). The NCEP-ATPIII but not the IDF criteria for the metabolic syndrome identify Type 2 diabetic patients at increased risk of chronic kidney disease. Diabet. Med, 25(12):1419-25. doi: 10.1111/ j.1464-5491.2008.02602.x.

Nelson, M.E., Rejeski, W.J., Blair, S.N., Duncan, P.W., Judge, J.O., King,A.C., Macera, C.A. \& Castaneda-Sceppa, C. (2007). Physical activity and public health in older adults: recommendation from the American College of Sports Medicine and the American Heart Association. Circulation, 39(8):1435-45.

Okosun, I.S., Annor, F., Esuneh, F., \& Okoegwale, E.E. (2013). Metabolic syndrome and impaired health-related quality of life and in non-Hispanic White, non-Hispanic Blacks and MexicanAmerican Adults.Diabetes Metab Syndr, 7(3):154-60. doi:10.1016/ j.dsx.2013.06.007.

Pattyn, N., Cornelissen, V.A., Eshghi, S.R. \& Vanhees, L. (2013). The effect of exercise on the cardiovascular risk factors constituting the metabolic syndrome: a meta-analysis of controlled trials. Sports Med, 43(2):121-33. doi: 10.1007/s40279-012-0003-z.

Puri, K.S., Suresh, K.R., Gogtay, N.J. \& Thatte, U.M. (2009). 
Declaration of Helsinki, 2008: implications for stakeholders in research. J Postgrad Med, 55(2):131-4. doi: 10.4103/00223859.52846.

Romo, V., Schwingel, A., \& Chodzko-Zajko, W. (2011). International resistance training recommendations for older adults: Implications for the promotion of healthy aging in Spain. Journal of Human Sport and Exercise, 6(4), 639-648. doi:http://dx.doi.org/10.4100/ jhse.2011.64.07

Sanders, M.E., Takeshima, N., Rogers, M.E., Colado, J.C. \& Borreani,

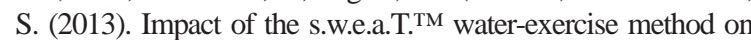
activities of daily living for older women. JSports Sci Med, 12(4):70715.

Sicras-Mainar, A.1., Navarro-Artieda, R. \& Ibáñez-Nolla, J. (2013). Clinical and economic characteristics associated with type 2 diabetes. Rev Clin Esp,214(3):121-30. doi: 10.1016/j.rce.2013.11.002.

Standards \& Guidelines for Aquatic Fitness Programming data revisited. (n.d.). Retrieved nov 16, 2014, from theAquatic ExerciseAssociation (AEA) Website,https://www.aeawave.com/Portals/2/PDF/ AEA_Standards_and_Guidelines14.pdf

Takeshima, N., Rogers, M.E., Watanabe, E., Brechue, W.F., Okada, A., Yamada, T., Islam, M.M. \& Hayano, J. (2002). Water-based exercise improves health-related aspects of fitness in older women. Med Sci Sports Exerc, 34(3):544-51.

Tan, S., Li, W. \& Wang, J. (2012) Effects of six months of combined aerobic and resistance training for elderly patients with a long history of type 2 diabetes. J Sports Sci Med, 11(3):495-501.
Tanaka, H., Monahan, K.D. \& Seals, D.R. (2001)Age-predicted maximal heart rate revisited. J Am Coll Cardiol, 37(1):153-6.

The guidelines of the National Cholesterol Educational Program Adult Treatment Panel-III (NCEP ATP-III), data revisited. (n.d.). Retrieved jan 16, 2014, from Third Report of the National Cholesterol Education Program (NCEP) Website, https:// www.nhlbi.nih.gov/files/docs/resources/heart/atp-3-cholesterol-fullreport.pdf

Thomas, J.R., Nelson, J.K., Silverman, S. \& Silverman, S.J. (2001). Textbook of research methods in physical activity 6 th. Ed. Human Kinetics, Champaign, Ilinois.

Villarreal, M. A., Moncada, J., Gallegos, J. J., \& Ruiz Juan, F. (2016). Effects of a Pilates-based exercise program on mood states in older adults in Mexico. Retos, 30:106-109.

Vincent, W.J.(1999). Textbookofstatistics in kinesiology 2nd Ed. Human Kinetics. Champaign, Ilinois.

Wang, X., Hsu, F.C., Isom, S., Walkup, M.P., Kritchevsky, S.B., Goodpaster, B.H., Church, T.S. Pahor, M., Stafford, R.S. \& Nicklas, B.J. (2012). Effects of a 12-month physical activity intervention on prevalence of metabolic syndrome in elderly men and women. J Gerontol A Biol Sci Med Sci, 67(4):417-24. doi:10.1093/gerona/ glr187.

Yamaoka, K. \& Tango, T. (2012). Effects of lifestyle modification on metabolic syndrome: a systematic review and meta-analysis. BMC Med,14;10:138. doi: 10.1186/1741-7015-10-138.

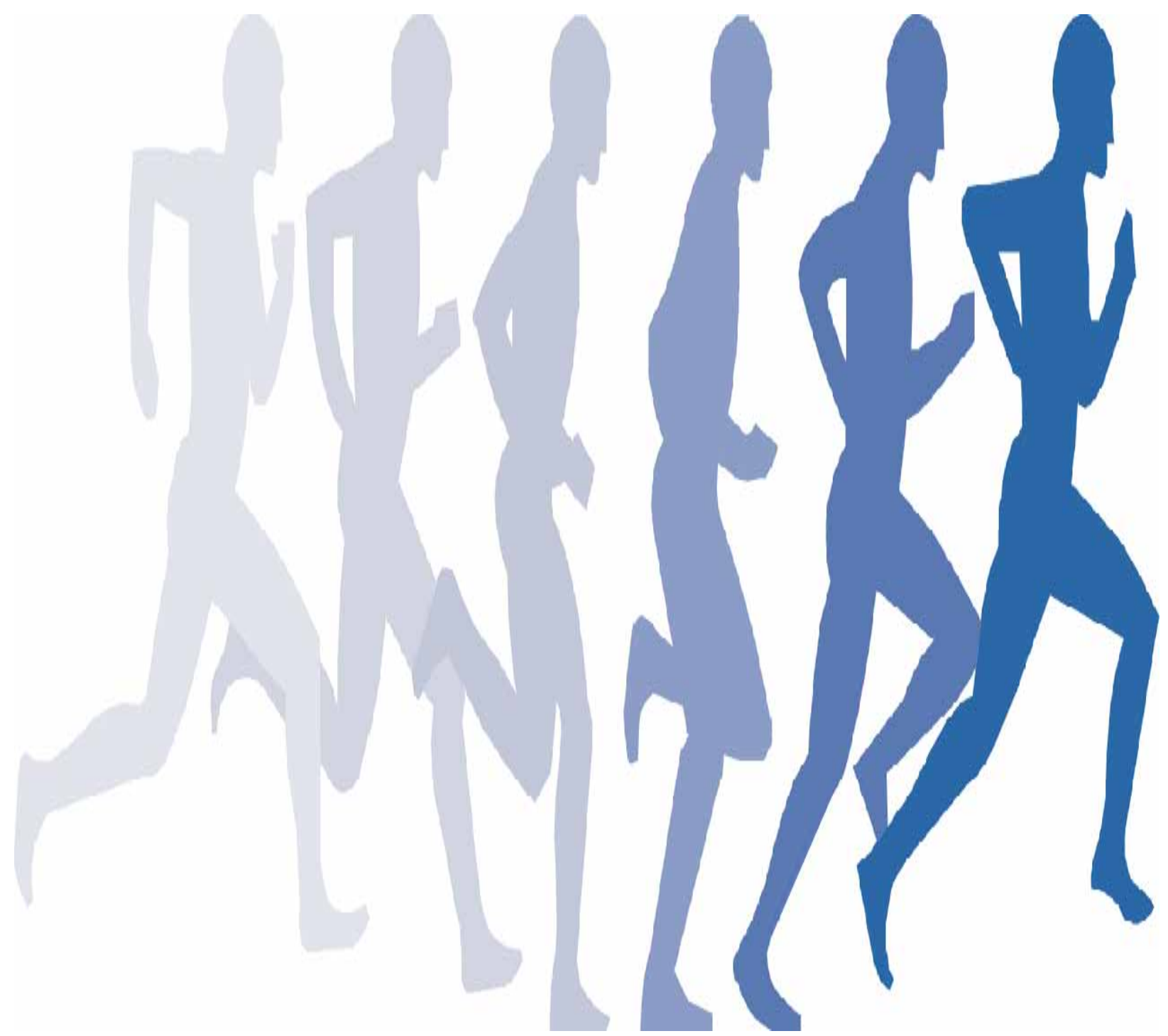

